\title{
Tinnitus: identifying the ominous causes
}

\author{
Anne Elizabeth Conlin MD, Emad Massoud MB, Eric Versnick MD
}

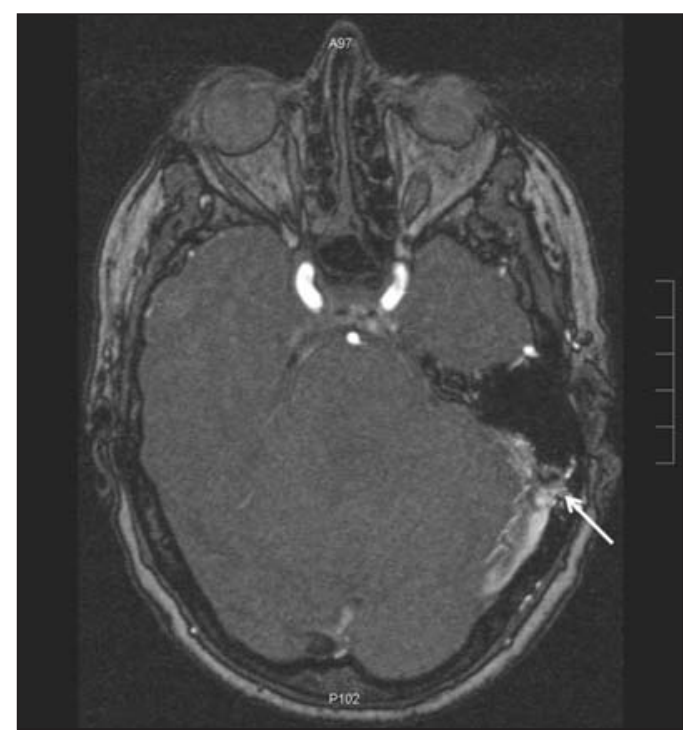

Figure 1: Magnetic resonance image of the head of a 67-year-old woman with pulsatile tinnitus. A dural arteriovenous fistula (arrow) and dural enhancement consistent with venous hypertension can be seen on the patient's left side.

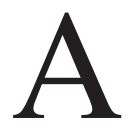

67-year-old woman presented with a constant, pulsatile, ringing in her left ear that had been ongoing for 12 months. She had no history of head trauma, surgery, hypertension or cardiovascular disorders. The patient was in no distress and appeared to be otherwise healthy. Findings on otoscopy and examination of the cranial nerves were unremarkable.

Given the patient's history of unilateral, pulsatile tinnitus, we auscultated her skull and heard a soft, high-pitched bruit over her left mastoid process. The bruit was more prominent when we asked the patient to turn her head to the left. We did not hear any such sounds over her neck, and the rest of the examination of her head and neck yielded normal results.

A computed tomography (CT) scan of the head showed a prominence in our patient's left cavernous sinus. There was no enhancing vascular mass and no evidence of herniation of the brainstem. Magnetic resonance imaging showed a dural arteriovenous fistula on the patient's left side, with prominent arterial supply from the left

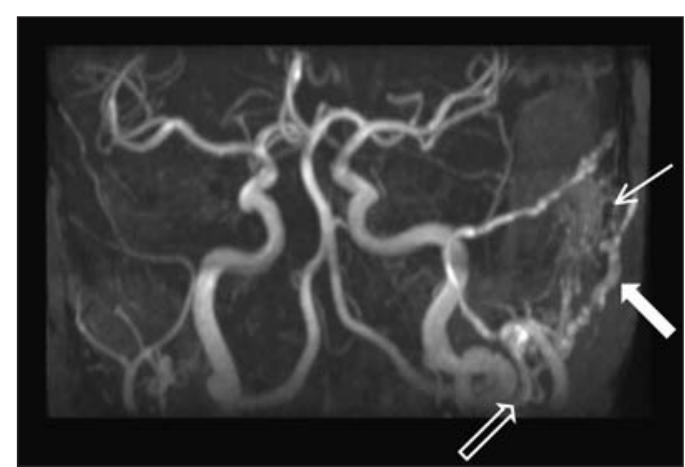

Figure 2: Magnetic resonance angiogram of the patient's cranial circulation. A dural arteriovenous fistula with prominent blood supply from the left occipital artery can be seen (thick white arrow). An enlarged external carotid artery (black arrow) and signal within the transverse sinus at the level of the fistula (thin white arrow) are also evident.

middle meningeal and left occipital arteries. There was also evidence of diffuse dural enhancement consistent with venous hypertension (Figures 1 and 2). Because we thought that the fistula might rupture and cause a cerebral hemorrhage, we referred her for urgent consultation with a neurosurgeon, who recommended a diagnostic catheter angiogram to document the anatomy of the fistula.

Treatment involved catheter-assisted coiling of the fistula using a Guglielmi detachable coil. There were no complications during or after the procedure. The patient's tinnitus resolved completely, and she has remained symptom-free for the past three years.

\section{- Ker POINTS}

- Nonpulsatile, bilateral tinnitus is usually benign, but pulsatile tinnitus may be the first presentation of a more serious condition.

- Patients with pulsatile tinnitus or unilateral tinnitus should be referred to an otolaryngologist, and patients with a history of head trauma or surgery should be referred urgently.

- Clinicians can differentiate between pulsaltile and nonpulstile tinnitus by taking a focused history, and a systematic physical examination can help to determine if the cause of pulsatile tinnitus is arterial or venous.

- Early intervention for patients with pulsatile tinnitus can help prevent potentially catastrophic sequelae. 


\section{Discussion}

Tinnitus, the perception of sound in the absence of an auditory stimulus, affects as much as $10 \%$ of the general population. ${ }^{1}$ The differential diagnosis of tinnitus is broad and includes potentially life-threatening conditions. ${ }^{1-3}$ Pulsatile tinnitus may be the first presentation of a more serious condition, whereas nonpulsatile, bilateral tinnitus is usually benign. Pulsatile tinnitus is reported by about $4 \%$ of patients who seek medical attention for tinnitus. ${ }^{1}$ The most common causes of pulsatile tinnitus are abnormalities of the carotid artery or jugular venous systems, which may require treatment. If left untreated, however, some vascular abnormalities can lead to catastrophic outcomes. ${ }^{3}$ An approach for diagnosing and treating some of the common causes of pulsatile tinnitus, based on a multidisciplinary clinical guideline, is outlined in Table 1 and discussed here. ${ }^{4}$

\section{Causes of pulsatile tinnitus}

Pulsatile tinnitus can be arterial or venous in origin. Atherosclerosis of the carotid artery can cause turbulent blood flow through stenotic segments of the vessel, which can lead to pulsatile tinnitus. ${ }^{3}$ Arteriovenous fistulas are thought to be acquired anomalies related to thrombosis of the dural venous sinus. The thrombosis may be spontaneous or secondary to trauma, surgery, neoplasm or infection. As the thrombosis resolves, artery-to-sinus anastomoses are formed. Mortality can be as high as $20 \%$ if the fistula ruptures. ${ }^{3}$ Arteriovenous malformations are similar to fistulas, but they are congenital and often remain asymptomatic until patients are 40-50 years old. Additional arterial causes of pulsatile tinnitus include dissecting aneurysms, fibromuscular dysplasia of the carotid artery and hypertension. ${ }^{3}$

The most common venous cause of pulsatile tinnitus is benign intracranial hypertension, also known as pseudotumour cerebri syndrome, a condition characterized by increased intracranial pressure in the absence of other neurological signs. ${ }^{1-3}$ Other venous causes include venous hum, which is generally caused by turbulent blood flow through the internal jugular vein; vascular neuroendocrine tumours of the skull base, such as a glomus tympanicum; and a highriding jugular bulb. ${ }^{3}$

\section{Clinical presentation of tinnitus}

A focused history and physical examination are essential in determinnig the differential diagnosis of tinnitus. Factors that should be assessed by the clinician include whether the tinnitus is pulsatile, continuous or episodic; the onset and location

\begin{tabular}{|c|c|c|c|}
\hline Origin & Cause & Clinical findings & Management \\
\hline \multirow[t]{6}{*}{ Arterial } & \multirow{2}{*}{$\begin{array}{l}\text { Atherosclerosis of } \\
\text { the carotid artery }\end{array}$} & Risk factors for atherosclerosis & \multirow{2}{*}{$\begin{array}{l}\text { Carotid } \\
\text { endarterectomy } \\
\text { or stent }\end{array}$} \\
\hline & & $\begin{array}{l}\text { Ipsilateral carotid bruit or thrill heard in } \\
\text { patient's neck }\end{array}$ & \\
\hline & \multirow{3}{*}{$\begin{array}{l}\text { Arteriovenous } \\
\text { fistula and } \\
\text { arteriovenous } \\
\text { malformation }\end{array}$} & $\begin{array}{l}\text { History of trauma, surgery, infection or } \\
\text { intracranial neoplasm }\end{array}$ & \multirow[t]{3}{*}{$\begin{array}{l}\text { Selective } \\
\text { embolization }\end{array}$} \\
\hline & & $\begin{array}{l}\text { Bruit auscultated over skull in the area } \\
\text { behind the ear }\end{array}$ & \\
\hline & & $\begin{array}{l}\text { Pulsating rhythm of bruit similar to } \\
\text { patient's pulse }\end{array}$ & \\
\hline & $\begin{array}{l}\text { Aberrant carotid } \\
\text { artery }\end{array}$ & $\begin{array}{l}\text { Otoscopy shows a beefy red mass } \\
\text { behind the anteroinferior quadrant of } \\
\text { the tympanic membrane }\end{array}$ & Reassurance \\
\hline \multirow[t]{5}{*}{ Venous } & \multirow{2}{*}{$\begin{array}{l}\text { Benign } \\
\text { intracranial } \\
\text { hypertension }\end{array}$} & $\begin{array}{l}\text { Typically seen in young female patients } \\
\text { with morbid obesity }\end{array}$ & \multirow[t]{2}{*}{$\begin{array}{l}\text { Reduction in } \\
\text { weight; diuretics }\end{array}$} \\
\hline & & $\begin{array}{l}\text { Headache, blurred vision, papilledema } \\
\text { and other features of increased } \\
\text { intracranial pressure without localizing } \\
\text { neurological dysfunction }\end{array}$ & \\
\hline & \multirow{2}{*}{$\begin{array}{l}\text { Venous hum and } \\
\text { high-riding } \\
\text { jugular bulb }\end{array}$} & $\begin{array}{l}\text { Tinnitus resolves with digital pressure } \\
\text { applied over the internal juglar vein }\end{array}$ & \multirow[t]{2}{*}{ Reassurance } \\
\hline & & $\begin{array}{l}\text { Otoscopy may show a blue mass behind } \\
\text { the tympanic membrane }\end{array}$ & \\
\hline & $\begin{array}{l}\text { Glomus } \\
\text { tympanicum }\end{array}$ & $\begin{array}{l}\text { Otoscopy shows reddish pulsatile mass } \\
\text { behind the tympanic membrane }\end{array}$ & Excision \\
\hline
\end{tabular}


(i.e., in one or both ears) of the tinnitus; any factors that exacerbate or relieve the symptoms; and the degree to which the patient feels distress, including his or her risk for suicide. ${ }^{5}$

Risk factors for pulsatile tinnitus related to atherosclerosis include disease of the peripheral vasculature, hypertension, angina, hyperlipidemia, diabetes mellitus and smoking. A history of head trauma or surgery may be associated with an arteriovenous fistula. ${ }^{1-3}$

A focused physical examination should include careful otoscopy to identify any vascular anomalies. A high-riding jugular bulb will appear as a blue mass in the posterior inferior quadrant of the middle ear space (Figure 3), ${ }^{6}$ whereas an aberrant carotid artery will appear as a beefy red mass in the anteroinferior quadrant (Figure 4). ${ }^{7}$ A glomus tumour presents as a reddish pulsatile mass behind an intact tympanic membrane (Figure 5). ${ }^{8}$ The neck and skull should be auscultated for bruits or venous hums over the carotid bulb, the jugular vein and the cavernous and dural sinuses.

To differentiate between venous and arterial sources, one can apply gentle digital pressure to the ipsilateral internal jugular vein. Resolution of the tinnitus implies a venous source, whereas persistence of the tinnitus implies an arterial source. An examination of the cranial nerves including funduscopy may show papilledema associated with benign intracranial hypertension. ${ }^{3}$

An audiogram can provide further diagnostic clues. Patients with pseudotumour cerebri may have a loss of hearing in the low-frequency

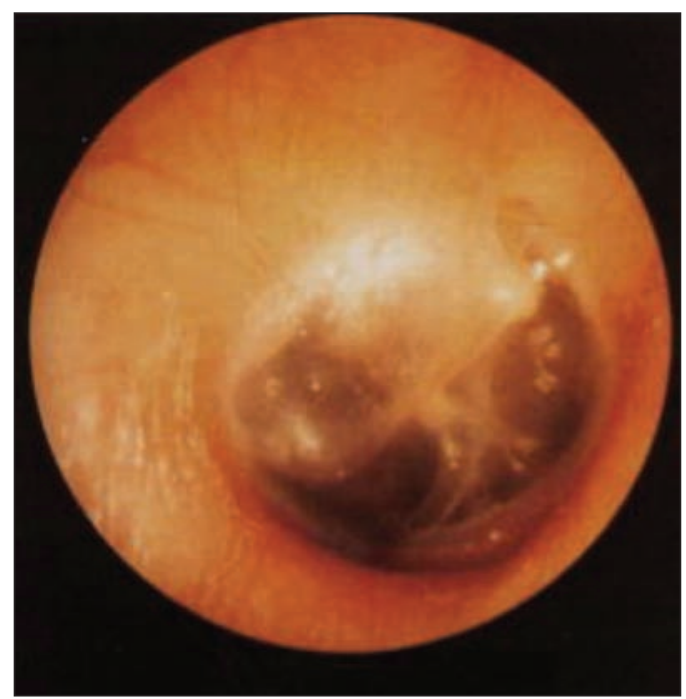

Figure 3: A high-riding jugular bulb, appearing during otoscopy as a purplish mass behind the intact tympanic membrane, in the right ear of a 12-yearold boy who presented with pulsatile tinnitus. Reprinted with permission from Laryngoscope 1997;107:321-7. Copyright @ 1997 John Wiley \& Sons, Inc. range, and tympanometry may show decreased compliance of the middle ear. Tympanometry can also be useful in identifying a glomus tumour. ${ }^{1}$ Testing with a tuning fork is nonspecific, because the patient may have conductive hearing loss, sensorineural hearing loss or normal hearing, depending on the cause of the tinnitus.

\section{Consultations and investigations}

All patients with pulsatile tinnitus or unilateral tinnitus should be referred to an otolaryngologist for further assessment. Patients with pulsatile tinnitus who also report a history of head trauma or surgery should be referred urgently.

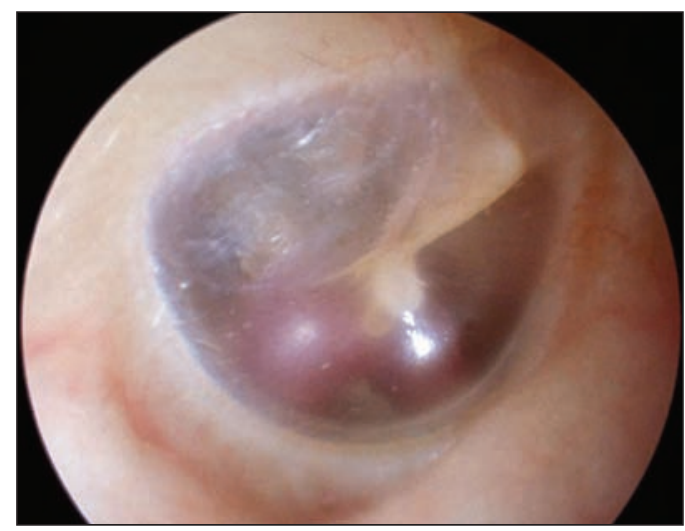

Figure 4: An aberrant carotid artery appearing during otoscopy as a curved reddish formation behind an intact and mobile tympanic membrane, in the right ear of a 28-year-old woman. Reprinted with permission from Arch Otolaryngol Head Neck Surg 2004;130:1120. Copyright @ 2004 American Medical Association. All rights reserved.

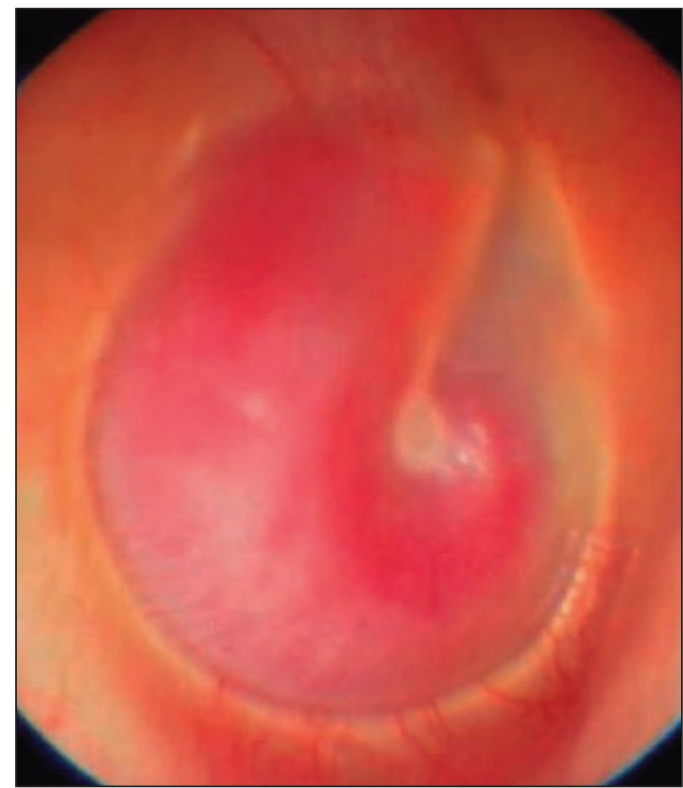

Figure 5: A glomus tumour. A reddish retrotympanic mass can be seen filling the middle ear space of the right ear. Reprinted from Acta Otorrinolaringol Esp 2007;58:426-33. Copyright @ 2007 Elsevier Limited. 
Radiographic assessment of pulsatile tinnitus is directed by clinical findings. When a retrotympanic mass is detected on otoscopy, a CT scan with contrast medium is the radiographic investigation of choice. ${ }^{4}$ A CT scan is appropriate for the detection of a glomus tumour, a high jugular bulb or an aberrant carotid artery. When a bruit is heard over the carotid artery, investigation by duplex ultrasonography can reveal stenosis of the vessel. ${ }^{3}$ In some cases of glomus tumours, magnetic resonance imaging is also helpful. ${ }^{1}$ In patients with normal findings on otoscopic examination and a clinical presentation that suggests arteriovenous malformation, arteriovenous fistula or fibromuscular dysplasia of the carotid artery, investigation with both magnetic resonance imaging and a magnetic resonance angiogram is indicated. ${ }^{1}$

\section{Conclusion}

Tinnitus is usually benign. However, a systematic approach to the physical examination and a detailed history from the patient can help clinicians identify the subset of patients for whom tinnitus may represent a more ominous condition.

\section{References}

1. Liyanage $\mathrm{SH}$, Singh A, Savundra $\mathrm{P}$, et al. Pulsatile tinnitus. $J$ Laryngol Otol 2006;120:93-7.

2. Crummer RW, Hassan GA. Diagnostic approach to tinnitus. Am Fam Physician 2004;69:120-6.

3. Sismanis A. Pulsatile tinnitus. Otolaryngol Clin North Am 2003; 36:389-402.

4. Biesinger E, Del Bo L, De Ridder D, et al. Algorithm for the diagnostic and therapeutic management of tinnitus. Tinnitus Clinic Network, Tinnitus Research Initiative. Available: www.tinnitus research.org/en/documents/downloads/TRI_Tinnitus_Flowchart .pdf (accessed 2010 Aug. 9 ).

5. Lewis JE, Stephens SD, McKenna L. Tinnitus and suicide. Clin Otolaryngol Allied Sci 1994;19:50-4.

6. Weiss RL, Zahtz G, Goldofsky E, et al. High jugular bulb and conductive hearing loss. Laryngoscope 1997;107:321-7.

7. Zahneisenl G, Kimmich T, Arnold W. Clinical problem solving: radiology. Aberrant internal carotid artery of the right middle ear. Arch Otolaryngol Head Neck Surg 2004;130:1120.

8. Herraiz C, Aparicio JM. Diagnostic clues in pulsatile tinnitus. Acta Otorrinolaringol Esp 2007;58:426-33.

Affiliations: From the Department of Otolaryngology (Conlin), University of Ottawa, Ottawa, Ont.; the Division of Otolaryngology (Massoud) and the Department of Radiology (Versnick), Dalhousie University, Halifax, NS

Contributors: All of the authors contributed to the writing and revising of the manuscript and approved the final version submitted for publication. 